\title{
EXPLORING MOBILE APPLICATIONS AND THEIR USAGE IN ENGLISH LANGUAGE LEARNING
}

\author{
Natalia Anggrarini $^{* 1}$, Ida Yulianawati ${ }^{* 2}$ \\ Natalia.anggrarini@unwir.ac.id ${ }^{* 1}$, ida.yulianawati@unwir.ac.id ${ }^{* 2}$ \\ English Education Department ${ }^{* 1,2}$ \\ Wiralodra University - Indramayu ${ }^{* 1,2}$
}

\begin{abstract}
The rapid development of information technology plays important role in English teaching. The form of technology in education is mobile devices. Mobile devices play an essential role in English language learning process for its variety of features. These potential features benefit the students to improve their English language ability. This case study explored the kind of mobile applications used in English language learning. By distributing questionnaire to eight teachers from five state senior high schools in Indramayu, the finding reported that the teachers used various mobile applications such as Schoology, Kahoot, Quizziz, WhatsApp group, Google classroom, Discord, and Electronic dictionary. The reasons to follow are the usability, availability, usefulness, portability, and persistence respectively. The teachers had reading skill dominantly as the target of improvement considered by the cognitive value and pedagogic coherence, accessibility, capacity and adaptability as the domination of quality criteria of mobile applications. This study implied the mobile applications support the teacher and students to have various media and learning material. It builds the students to be more independent and have self-study. In addition, the pedagogical and practical design for the use of mobile applications in language learning should be well arranged to cover more skills to improve.
\end{abstract}

Keywords: Mobile device, Mobile application, Smartphones, English language learning, Learning model,

DOI: $\underline{\text { https://doi.org/10.31943/wej.v4i2.112 }}$

\section{INTRODUCTION}

The remarkable entry of technology has changed the tradition of English language. Smartphones, tablets, and computers take people worldwide to connect in one touch of fingers (Baros \& Al, 2019). More activities are done with the help of mobile device include in English education. Numerous applications such as Google Classroom, Scoology, Quizziz, are available for the students to learn English (Muthia et.al., 2013; Gangaimaran \& Pasuphati, 2017; Rahayu \& Purnawarman, 2018); the students or the teachers can download whether free or paid the applications and use them in the learning activity. Many pieces of research deal with the investigation of mobile learning. Vocblast (Ali \& Ghazali, 2016) was used in the ESP learning of Technical students in Malaysia. MIM (Mobile Instant Messaging) was used in Spain for university students to see the accuracy in language writing (Andujar, 2016) in (Klimova, 2019). While MIM 
was used to see the accuracy of English Verbs and English irregular Verbs in language writing in Mauritian (Fakooa et.al., 2019) and Angliicina as an application used to teach vocabulary in Czech Republic and confirmed as practical application (Klimova, 2019).

Previous research showed that various mobile applications were used to support English language learning with their main focuses of improvement, such as vocabulary, writing, verbs, and soon. Those focuses of improvement become consideration from the teachers to choose the most appropriate application they can use in the classroom. By the ease of access, the students can download the application freely thorough the provided platform.

Considering the numerous mobile applications that can be freely downloaded by the teachers and the students in those previous researches, this study aims to explore the mobile applications suggested by eight senior high school teachers in Indramayu, Indonesia. So, the research questions developed are:

1. What mobile applications are used in senior high school?

2. What is the usage of those mobile applications?

3. What skills are improved from those application?

\section{LITERATURE REVIEW}

\section{Mobile Applications for Language Learning}

Mobile devices such as mobile phones and tablet PCs have been integrated in the process of language learning recent years. The existence of mobile devices support the teaching and learning as the enhancement in mobility and connectivity create a way for the students to access many information provided in the internet to learn English. Zou \& Li (2015) confirmed that the students have a way to across different cultures to learn English through mobile devices.

Zou \& Li (2015) mentioned one of mobile application, Moodle as a platform for the students to learn virtually during the study. They also elaborated some mobile applications that can be used for language learning. This condition potentially explore more information and set more chance for the students to get various ways of learning as well as material to learn language. The mobile applications used in language learning are designed to support the improvement of language skills such as listening, speaking, reading and writing whether inside or outside the classroom. The activities covered by the mobile applications is unlimited. They can do blended learning in the learning process such as in application of Kahoot (Muthia, 2018). The interaction build in mobile applications provide the students a forum to have communication, written or spoken through the mobile devices. Whatsapp or Wechat (Zou \& Li, 2015) has the feature of group forum to have wider interaction for the members.

Beside the communication in form of written and spoken, mobile applications also designed to have interactive activity for the language learning. Rahayu \& Purnawarman (2018) reported that some mobile applications could increase students' motivation and autonomy by making instant feedback and review by using gamified platform such as Kahoot, Quizziz, Edupuzzle and Quizlet. This kinds of activity build the students competency in term of self-assessment.

Mobile applications served in mobile devices help the teacher to manage the learning activity in effective way. Zou \& Li (2015) confirmed this by 
examining google classroom (GS) as an effective learning platform that served as Learning Management System (LMS). He reported Google Classroom as a free tool that can be used in any tertiary level educational institute to develop learning management system. He found GS as an effective platform where students can involve in a variety of activities with persistence and usability of the application. Schoology also regarded as learning platform that served as Learning Management System (LMS). Mutia (2018) reported that Schoology gives easiness, security, and efficiency for the students in learning. Those mobile applications chosen by the teacher to be used in learning process must have some characteristics and purposes. This characteristics are of course in line with the objective of the learning process.

\section{Mobile device Characteristics}

As informed by Fakooa et.al (2019), 90\% of people in developed countries own and enjoy using mobile devices, with $92 \%$ of 18 -29-year-olds owning one. It means that most people have their mobile devices and enjoy using it. They get benefits in using mobile device by the features and characteristics. Mehdipur \& Zerekahfi (2018) mentioned that mobile devices have several characteristics, they are;

1. Portability: the technology is available whenever the user needs to learn

2. Individually: the technology can be personalized to suit the individual learner's ability, knowledge and learning style, and is designed to support personal learning rather than general office work

3. Unobtrusiveness: the learner can capture situations and retrieve knowledge without the technology becoming overly noticeable or imposing on the situation

4. Availability: the technology can be used by the learner anywhere, to enable communication with teachers, expert, and peers

5. Adaptability: the technology can be adapted to the context for learning and the learner's evolving skills and knowledge

6. Persistence: the learner can use the technology to manage learning throughout a lifetime so that the learner's accumulation of resources and knowledge will be immediately accessible despite changes in technology

7. Usefulness: the technology is suited to everyday needs for communication, reference, work and learning

8. Usability: the technology is easily comprehended and navigated by people with no previous experience using it.

By those characteristics, it is no wonder that mobile devices are nowadays widely used in education, especially in language learning. By its characteristics, mobile devices are portable for studying anywhere at any time, whether for formal and informal in blended or collaborative learning as well $(\mathrm{Oz}, 2013)$.

\section{Mobile device Application Quality Criteria}

The mobile devices' characteristics make it clear that the mobile device can be used to assist learning, especially in language learning. Thus, the teachers should be careful in evaluating good mobile applications that can be suggested to the students. Pilar \& Cristina (2013) stated that the mobile applications used in the classroom should meet students' needs. The mobile applications have to meet the 
educational purposes. It means that the use of mobile application should be appropriate with the goal of learning. The quality of mobile applications has been adopted by Pilar \& Cristina (2013) from Fernandez-Pampillon Casteros et.al (2012) and Klimova \& Berger (2018) listed in the table below:

\section{Table 1. Quality Criteria of Mobile Application from Learning Objects to} Educational Applications

\begin{tabular}{ll}
\multicolumn{1}{c}{ Quality Criteria } & Adaptation to Educational Application \\
\hline 1. Goals and pedagogic coherence & 1. Cognitive value and pedagogic \\
2. Content Quality & coherence \\
3. Capacity to generate reflection, & 2. Content Quality \\
critical thinking, and innovation & 3. Capacity to generate learning \\
4. Interactivity and adaptability & 4. Interactivity and adaptability \\
5. Motivation & 5. Motivation \\
6. Format and layout & 6. Format and layout \\
7. Usability & 7. Usability \\
8. Accessibility & 8. Accessibility \\
9. Reusability & 9. Visibility \\
10. Interoperability & 10. Compatibility
\end{tabular}

From the table, the quality of the mobile application is evaluated before it is suggested to the students. In terms of cognitive value, the teacher should consider the target user's specifications and goals (Pilar \& Cristina, 2013). Like the previous researches, some applications were given based on the target of the improvement. The target of learning improvement should be hand in hand with the rest criteria such as the content, capacity to generate learning, interactivity, motivation, the format, layout, usability, accessibility, visibility, and compatibility.

\section{METHOD}

\section{Research Method}

This research aims at exploring the use of mobile applications in English language teaching in senior high school. Thus, a qualitative approach is used by applying descriptive analysis. Cresswell (1998) as cited in Marshall \& Rossman (2006), qualitative research is used to explore and describe the phenomenon in a particular setting. It discusses biography, phenomenology, grounded theory, ethnography, and case study as the major strategy. He also states that qualitative research is a study that helps the researcher to empower individuals to share their stories, concepts, and thought.

This research finds out and describes a temporary phenomenon in the context of mobile applications in English language learning; case study then becomes the design of this research. Case study investigates a contemporary phenomenon within the real context. In this case, the setting will be mobile applications; the researchers explored the variety of mobile applications used by the teacher in senior high school (Marshall \& Rossman,2006). It means that the researchers is only to cover what is in the field. This is supported by Marshall and Rossman (2006) that a case study is preferred in examining contemporary events, but when the relevant behaviors can not be manipulated. 


\section{Research Participant}

This research took the group of teachers who used mobile applications in teaching and learning English, whether inside or outside the classroom. There were eight teachers - five females and three males with the age ranged in 30-40 year old participated voluntary in this research. They were from five different state senior high schools in Indramayu.

\section{Data Collection}

Marshall and Rossman (2006) stated that the data collection of qualitative research shows several ways that can be done, such as asking the question, observing directly, interviewing in-depth, and analyzing the documents and material culture. Therefore, this research distributed questionnaire as a data collection method through google form due to the Covid-19 Pandemic. Questionnaires are instruments that present respondents with a series of questions or statements to which they are to react either by writing out their answers or selecting from among existing answers Marshall and Rossman (2006). The questionnaire typically entails several questions with structure response categories; some open-ended questions may also be included.

\section{Organizing and interpreting Data}

The data are organized and interpreted by considering several aspects (Marshal and Rossman,in Sana'ababneh, 2017).

1. Collect the data

2. Think about the data concerning the research project

3. Categorize the data

4. Reflect on the data (write notes, memos, comments, etc.)

5. Organize the data in different ways to find previously unseen patterns and connections

6. Connect the emerging issues and themes to concepts and theories that may help explain them

7. Collect more data, based on the directions suggested by previous analysis

\section{FINDING AND DISCUSSION}

This study aimed to answer the research questions; the mobile used by the teacher; the usage of the mobile applications in English language learning and the target of improvement. The study involved eight teachers from different State Senior High Schools. Due to the Pandemic Covid-19, the data collection was conducted via online. The questionnaires were arranged in google form so the participants filled the questionnaire in google form. Here are the finding as well as the discussion of the research.

\section{The Mobile Applications Used by the Teachers in English Language Learning}

This research explored the use of mobile applications by the teacher in English language learning. The data was gained after the researcher distributed the questionnaires via google form to the participants. It was confirmed that from eight teachers, six teachers used mobile devices in English learning activity and two teachers used mobile device only in certain time. 
The teachers used mobile devices when the activity needs the students to use application in learning activity. From the data it is found that the teaches from eight senior high schools in Indramayu use several certain applications such as schoology (Muthia, 2018), kahoot, quizziz (Rahayu \& Purnawarman, 2018), WhatsApp group, google classroom, discord (Wulanjani, 2018), and electronic dictionary (Hayati \& Fattahzadeh, 2006; Abhogunaim, 2019; Laufer et.al., 2006). Most of the teachers used Google Classroom in their learning process. Google Classroom was considered as good learning management system. T3 said that "They are good as Learning Management System, and Communication Management System”. T3 gave activity in Google Classroom as an alternative way during the online meeting, the teacher believed that GS has good LMS and CMS. This opinion is supported by Gurunada (2020) who said that google classroom (GS) is an effective learning platform that served as Learning Management System (LMS)(Turnbul, 2019). GS gives features that allow the teacher to manage the material and link it to the other sources such as youtube. T5, T6, T7, and T8 said that GS is easy to use and simple.

\section{The Usage of The Mobile Applications and Skill to improve in English}

\section{Language Learning}

The mobile applications were used, first is to utilize the mobile device in learning activity, T1 "I use mobile device to utilize the application. I allow them to use mobile device during the English language activity so they can make useful of their mobile device". The teacher thought that it will be more useful when the students can utilize their mobile device for the sake of English learning. The use of mobile devices allows the students to access the information related to material wider in the internet. Nalliveetil \& Alenazi (2016) reported similar condition where the teachers allow their students to use mobile devices in English learning activity to access information. Sana'ababneh (2017) supported that technology allows the students a more freedom and time to have easy access to the internet through their phone to make use of learning resources. With that condition, allowing students to utilize mobile devices make them easy to look for the sources and information related to the material they learned in the class. This also gives them chance freely choosing resources from any kinds of source they need from the internet.

By the chance the students get in utilizing mobile device, the learning is more meaningful and richer. They can search for information and resources from the internet to support their material. Hence, the second is the use of mobile device encourages the students to have various learning media. Like T5 "I usually ask the students to find the information related with the learning material by accessing the internet from mobile device. However, the textbook I used contained the audio and video file that should be accessed from mobile device. So, it supports the learning activity especially when we need media". In this matter, T4 underlines the use of mobile device is to explore the various media which gathered by utilizing the mobile device. They are not bounded to access only the textbook as media in learning. But they can get more media such as audio and video from internet. Furthermore, this actually implies the use of mobile device in case of accessing the internet guides the students to be more active in participating at the learning process. It is supported by Klimova \& Berger (2018) who mentions that the suitable tools in mobile device can motivate students to learn 
interactively. T5 further mentions "In addition, I let students to find the unknown vocabulary from their online dictionary at mobile device." The information can be from the internet or from the dictionary application. The purpose is to support the learning activity. Klimova \& Berger (2018) state in his research that the activities the students do in their mobile device refer to electronic dictionaries for completing the assignment.

The involvement of students by utilizing the mobile device actually guides them to build the independent learning. In this matter, the students have the opportunity to actualize the participation by finding the material that is suitable with their needs of learning. Thus, the third is the use of mobile device get the students self-study. As mentioned by T5 "I let students to find the unknown vocabulary from their online dictionary at mobile device". In this matter, the teacher gives the students space to have their own effort in acquiring the new vocabulary through online dictionary. It is considered as the effective way to improve the vocabulary. As supported by Klimova \& Berger (2018) the use of mobile application contributes to the improvement of students' learning specifically at English vocabulary and phrases. It means that the students can develop their vocabulary knowledge by finding and understanding the meaning of unknown vocabulary. This vocabulary knowledge then actually supports to the learning process. Since the students have more understanding to the topic material due to their vocabulary knowledge, the goal of learning can be accomplished.

Moreover, the students also practice their self-study by using the other media. Like T7 "I ask students to find material (text, video, picture) that related with the topic". This reveals that the teacher realizes the needs to support students for their independent learning by asking them to access the internet during the learning process. This also confirmed by Anggrarini \& Wati (2019) in their research that the teacher need to help the students to look for information or sources they need from the internet by the mobile devices. However, the guidance of teacher is really needed to ensure the students decide the suitable material related to the topic. As confirmed by Klimova \& Berger (2018), the teacher can lead to the independent learning by providing the professional and careful guidance. It means that even the students find the material by accessing the internet for example, the teacher should take control of it.

The use of mobile applications based on the teacher's consideration which is achieved from the questionnaire about the reasons behind the choice of mobile devices to support English Language Learning.

\section{Chart 1. The reason in using mobile devices application in English language} learning

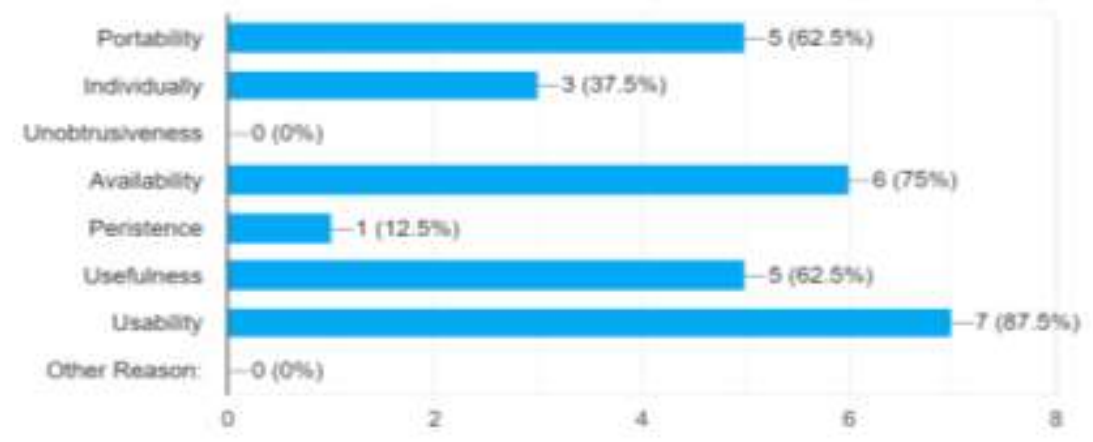


According to the chart above, the reason of using mobile devices in supporting English language learning consists of six points. They are usability, $87.5 \%$; availability, $75 \%$; usefulness, $62.5 \%$, portability, $62.5 \%$; individually, $37.5 \%$ and persistence, $12.5 \%$ respectively. The usability refers to the technology that is easily comprehended and navigated by people with no previous experience using it (Mehdipour \& Zerekahfi, 2013). T1 stated that "those applications are easy to use and simple". In this case, T1 utilizes the Schoology, Kahoot and Quizziz as the mobile application. For instance, in matter of Quizziz, it is easy to use for students, because it presents the understandable features. As found by Rahayu \& Purnawarman (2018) Quizizz has two features of feedback, including the game summary (score and rank) and the performance stats (the number of correct and incorrect answers, the number of unattempt questions, average time per question, and the longest streak). The features of Quizziz show the similar pattern in the other mobile games which have the score and rank. However, they were utilized as the feedback for students to have their self-assessment in learning grammar. This is considered as the reason of usability for the mobile application. It is since the students have involved the similar environment in case of mobile application, they are easier to adapt and use the learning application, such as Quizziz.

The second reason of mobile applications used by the teacher is availability. Mehdipour \& Zerekahfi (2013) defines the availability as the technology can be used by the learner anywhere, to enable communication with teachers, expert, and peers. This reason is in line with T2 "For learn and study at home". It implies that the use of WhatsApp group facilitates both the teacher and students to conduct the learning activity even they do not have the face to face meeting. It means that the different location of teacher and students does not become the burden in the learning activity. It is supported by Sana'ababneh (2017) who states that the technology in form of mobile application represents the smarter features that extend beyond the walls of the school or the confines of a class period. It reveals that the learning process allows the students to learn at their own time and anywhere which means the activity can take place in formal or informal settings. Following that, since the WhatsApp has the features of chatting, sharing the file, voice and video call, it facilitates the quick and easy way of communication for teacher and students. As stated by Sana'ababneh (2017) there is an accelerated demand for the communication due to the development of electronic gadgets. Regarding to this study, the invention of mobile application such as WhatsApp guides the teacher and students to approach easily one to another.

The usefulness becomes the third reason in using mobile application. Usefulness belongs to the technology that is suited to everyday needs for communication, reference, work and learning (Mehdipour \& Zerekahfi, 2013). The use of mobile application is perceived being useful in facilitating the learning activity. There are two teachers who assert the useful gained when the students access the dictionary. T5 says "I suggest my students to use U-Dictionary because I think it is the proper bilingual dictionary for students who needs some example for the vocabulary that they learn. In addition, there are so many features, which involve spelling check, writing club and word games". Then it is followed by T7 "For dictionary application, Dictionary can make students learn vocabulary easily. Not just vocabulary but also the pronunciation of the vocabulary". 
According to the both teachers, the use of dictionary helps the students to learn vocabulary. The students do not only learn to find the meaning of words, but also how to perform those words. In this case, they practice the spelling and pronunciation of words. This condition is supported by Rahayu \& Purnawarman (2018), the use of electronic dictionaries improves the students' opportunity to learn new vocabularies in foreign language. It is mentioned that the students have more interest and motivation to learn new words because they use electronic dictionaries.

The fourth reason is portability. Mehdipour \& Zerekahfi (2013) defines the portability as the technology is available whenever the user needs to learn. It means that the technology in form of mobile application grants the teacher and students to involve in their learning activity anytime. This study found the most frequent mobile application used by the teacher refers to google classroom. From the questionnaire, there are four teachers who utilize google classroom. Google classroom is perceived easy to use. As mentioned by T3 "Easy to use", T4 "Easy to apply", and T6 "It's easy". This condition is supported by Sudarsana et.al (2019) who acknowledges that google classroom provides a central site for communicating with students, sending feedback and providing homework. It implies that the google classroom facilitate several needs in learning. Furthermore, the portability of google classroom is stated by T8 as the combination of Learning Management System (LMS) and Content Management System (CMS). It means that the google classroom offers the teacher easier access to develop the material and track the students' progress in learning. As said by Turnbul et.al (2019) CMS refers to essentially software applications designed for the creation and management of digital content in a collaborative environment. Ninoriya et.al (2011) also states that LMS focuses on the tracking registration, attendance class lists, grades, test results, class scheduling, other administrative requirements of schools and instructor-led classes. In other words, LMS helps in running a learning organization.

Persistence becomes the last reason found in case of using mobile application for English language learning. Mehdipour \& Zerekahfi (2013) elaborated persistence as the use of the technology to manage learning throughout a lifetime so that their accumulation of resources and knowledge will be immediately accessible despite changes in technology. It means that technology gives the students light approach to access their material for example. Schoology as one of mobile application practiced by teachers that has persistence as the reason. Byrd (2013) mentions that the teacher can supply student resources to be reviewed at any time through Schoology. It means that the students are able to improve their understanding since they can review the additional sources whenever they need. In addition, Muthia et.al (2018) asserts the benefits of Schoology is realized in making the lessons enjoyable and increasing students' self-confidence and responsibility. Schoology allows the students work collaboratively with peers. Then they receive the assignment which is followed by the feedback in controlled setting (Byrd, 2013).

\section{The Target of Improvement based on Mobile/ Smartphone Application Used}

The use of mobile applications do not limit the implementation of the learning process. It is conducted to reach the goals of learning which is revealed 
the improvement of students. In this matter, the teacher has the target for students' improvement as the output of learning process. It is started by the skills that the teacher expected to be improved by the suggested mobile application. Then it is followed by the quality criteria from learning objects to educational application. The data were presented in the chart as follow:

\section{Chart 2. The Target of Improvement based on Mobile/ Smartphone} Application Used
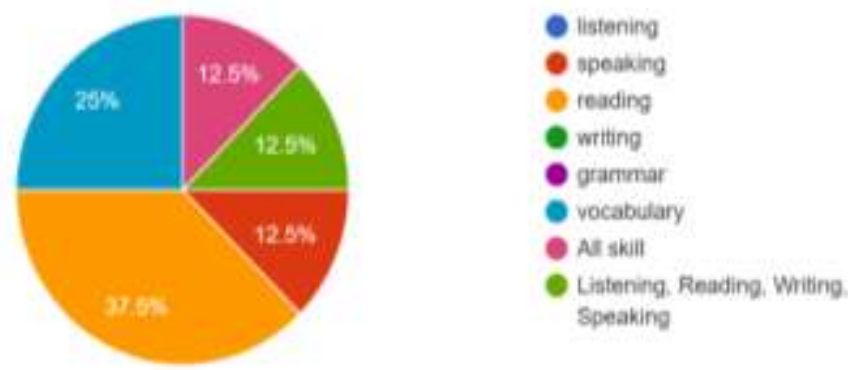

From chart 2, there are five skills expected to be improved: reading (37.5\%), listening (25\%), speaking (12.5\%), writing (12.5\%), and all skill (12.5\%) respectively. This associates with the mobile application used by the teacher.

In this study, the high percentage of reading as the target of improvement is indicated by the use of electronic dictionary. T5 states "Then, for the online dictionary I suggest them to use U-Dictionary for bilingual dictionary and Oxford online dictionary for monolingual dictionary". In this matter, the teacher considers the importance of students to consult to the dictionary during the learning process. This condition is supported by Laufer (as cited in Hayati \& Fattahzadeh, 2006) who believes that when the students encounter words which are familiar but the context is not, then they are encouraged to consult the dictionary. Moreover, the teacher suggests two kinds of dictionary to the students, including monolingual and bilingual dictionary. According to Nation (2013) monolingual dictionary is used to interpret the definition, examples and the word form. In other side, Aboghunaim (2019) finds that bilingual dictionary is preferred by students due to the more precise and detailed information presented specifically in finding the meaning of unknown words. Both monolingual and bilingual dictionary helps the students to build their vocabulary knowledge. As the result, the students are easier to find the meaning of words when they engage in reading. Therefore, the students may build their reading comprehension related to the text or learning material. It is in line with Aboghunaim (2019) who finds that both monolingual dictionary and bilingual dictionary have an impact on teaching vocabulary, specifically bilingual dictionary results in a high reading speed. This condition occurs as said by T5 "I can see that they have good vocabulary knowledge related to the topic of learning material discussed". Furthermore, Laufer et.al (2006) asserts that the bilingual dictionary provides easy access for students to understand the materials they read. In other words, the students acquire the meaning of words from the dictionary and this knowledge is useful to build the reading comprehension.

The other skill expected to be improved refers to listening which is followed by speaking. One of reasons behind these targets is the use of discord in the English learning process as practiced by T3. According to Lacher (2018) discord is a popular voice chat application that allows for Voice over Internet Protocol (VOIP) and messaging between users. Discord is considered as an appropriate 
mobile application in facilitating the listening and speaking activity because it allows the teacher and students to share their voice and give the response of it. As found by Wulanjani (2018) the students are mostly engaged in many tasks which forced them to always give their respond actively. Discord facilitates the teacher to have speaking and listening activity even it is not at face to face meeting. Furthermore, the attention to the students' listening skill is also showed by T7 who utilizes the voice recorder as one of mobile application to help the listening activity. In addition, she guides the students to use dictionary in learning the pronunciation of words. It implies that the students consider one of speaking aspect, pronunciation. The pronunciation which associates with producing the words clearly is important because it influences the listeners' understanding to achieve the meaning of messages. It is in line with Prashant (2018) who stated that pronunciation played an important role in English speaking to express the ideas. Specifically Brown (2003) supports that speaking belongs one of communication skills which has closely relationship with listening in pragmatic view of language performance. It means that the speaker and listener negotiate the meaning of what they utter by expressing it verbally. Thus, the sense of listening and speaking is getting the understanding of others to build communication. As the result, it actually reveals the use of discourse, voice recorder and dictionary provide the multimedia content which offers more opportunities for the students to be engaged and participated more actively in case of listening and speaking.

Regarding to the implementation of online learning, the teacher has the target of improvement in matter of all skill. It is indicated when most of teacher use more than one mobile applications. This occurs since the teaching and learning of English requires the integration of all skills, which involve reading, listening, writing and speaking. As supported by Pardede (2019) the integrated-skills approach is believed as an effective way to develop the students' communicative competence and the ability to use English in case of gaining access to social, vocational, educational, or professional opportunities. In this matter, the teacher has an awareness to accomplish the goals of learning by facilitating the students to practice all English skills. However, one mobile application is perceived not enough to engage students for concerning their four English skills. This circumstance is supported by T7 "I hope there is application that can help teacher and students that provide material books or articles, we can use dictionary feature in that application. Not just that, the application that can upload and download material or assignments (picture, video). And those are in one application". It implies that the teacher needs more features in conducting the process of online teaching and learning that is packaged in one application only. This consideration is actually based on the quality criteria of mobile application that meets the needs of learning. In this case, the teacher considers the quality of cognitive value and pedagogic coherence (62.5\%). According to Pilar et.al., (2013) cognitive value and pedagogic coherence deals with the teaching goals, the target users and the skills to be developed. It means that the teacher realizes the important of coherence between the goals/ users (teacher and students)/ skills and the app's contents. In simply, the teacher hopes that the content of application provides the needs of learning process. In addition, it is accessed easily by the teacher and students as the user of application. Furthermore, the content of 
application facilitates the teacher to conduct the activity by integrating all English skills for students.

\section{Chart 3. The Quality Criteria from Learning Objects to Educational Application}

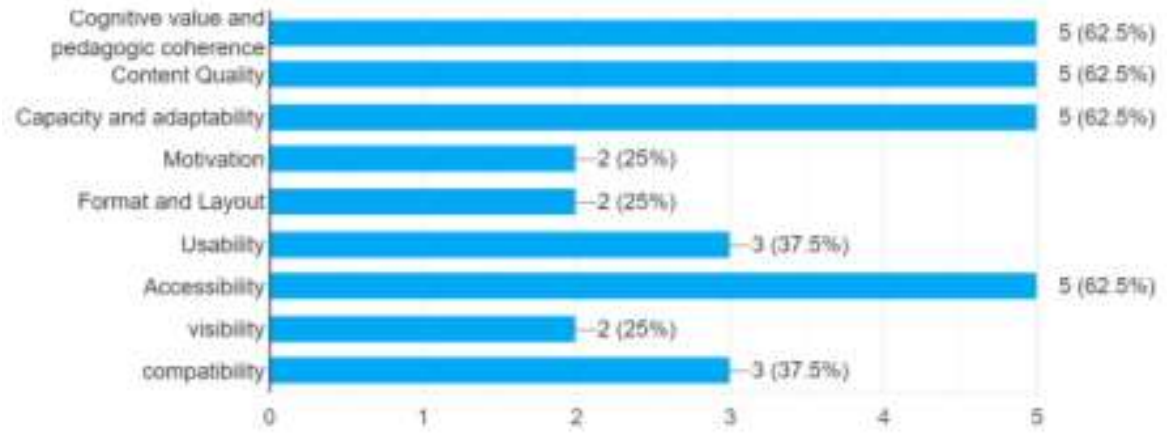

The target of learning improvement should be hand in hand with the quality criteria. As presented in the chart 3, there are three quality criteria that dominates the teachers' answer, which involve coherence, content quality; accessibility; capacity and adaptability in $62.5 \%$. Then there are usability and compatibility for $37.5 \%$. After that, motivation, format and layout, and visibility takes $25 \%$.

On account of the target of improvement, the teacher also considers the other quality criteria of mobile application. It is shown by T4 "I hope in the future, the application developers can create the application easier to apply by the beginners, and do not need much charge in applying the application". It implies the teacher takes the accessibility $(62.5 \%)$ to decide the target of improvement. It means that when the mobile application presents the light approach, it is easier to meet or deal with the skills expected to be improved. Following that, there is capacity and adaptability $(62.5 \%)$ that associates to the ease with which the mobile application adapts to the different types of users, including the teacher and students as mentioned by Pilar et.al., (2013). In this matter, the teacher considers that the different competence level of students does not bring the meaningful difficulty when the mobile application can propose the different contents and activities. In addition, the mobile application can be used independently of specific teaching or learning methods which adapt the needs of learning. Based on the quality criteria of mobile application, it reveals that the teacher observes the needs of teaching and learning process before there is the target of improvement for the students. Following that, the teacher has an attempt to achieve the target of improvement by utilizing the certain mobile application.

\section{CONCLUSION}

The study underlines the use of mobile application is accountable for learning in different situation. There are several mobile applications used by teachers in this study, including schoology, kahoot, quizziz, WhatsApp group, google classroom, discord, and electronic dictionary. The use of these application is based on the usability, availability, usefulness, portability, and persistence respectively. This study further points that the teachers have the target of improvement by accessing the mobile application. They have the target in case of reading, listening, speaking, writing and all skills respectively. Moreover, these targets were arranged by considering the quality criteria of mobile application. 
The quality criteria of the mobile applications used in English learning process are cognitive value and pedagogic coherence, accessibility, capacity and adaptability. This study implies the pedagogical and practical design for the use of mobile applications in language learning to cover more skills to improve. This study also leads the other researcher to explore more information deal with the use of mobile application in the students' point of view.

\section{Acknowledgment}

This research was supported by the Research Fund provided by Directorat of Research and Community Service, Directorate General for Research and Development, Ministry of Research, Technology and Higher Education. In accordance with the Research Contract for Fiscal Year 2020. The research scheme was "Penelitian Dosen Pemula"

\section{REFERENCES}

Aboghunaim, N. M. (2019). The Effect of Monolingual and Bilingual Dictionary on the Foreign Language Learners' Acquisition. International Journal of Applied Linguistics and Translation. Vol. 5, No. 4. 55-57

Ali, Z., \& Ghazali, M. A. (2016). Learning Technical Vocabulary Through a Mobile Application: Language Teacher Perspective. IJLEAL, 10.

Andujar, A. (2016). Benefits of Mobile Instant Messaging to develop ESL Writing. System, 1-14.

Anggrarini, N \& Wati, A. (2019). Utilizing Blog in Elt Writing to Non-English Major Undergraduate Students of Wiralodra University. Wiralodra English Journal (WEJ) Vol 3 No 2. P $314-328$.

Brown, H. D. (2003). Language assessment: Principal and classroom practices. United State: A person Education, Inc.

Byrd, A. (2013). Shoology (Review). Retrieved from C, S., D, M., Barros, \& al, C. J. (2019). Mobile Applications and Their use in Language Learning. Springer, 10.

Chinnery, G. (2006). Going to the MALL: Mobile Assisted Language Learning. Language Learning and Technology, 9-16.

Cresswell, John W. (1998). Qualitative Inquiry and Research Design, Choosing Among Five Tradition. California: SagePublication.

Fakooa, B., Banon, M. B., \& Gobin-Rahimbux, B. (2019). A Smart Mobile Application for Learning English Verbs in Mauritan Primary Schools. Springer, 399-409.

Fernandez-Pampillon Casteros, A., Dominguez Romero, E., \& Armas Ramero, I. (2012). Heramienta de Evalucion de la Calidad de Objectos de Aprendizaje (herramienta COda):Guia Para la production y evaluacion de materiales didacticos digitales (Version 1.1). Madrid: Universidad Complutense. 
Gangaimaran, R., \& Pasuphati, M. (2017). Review of Use of Mobile Apps for Language Learning. International Journal of Applied Engineering Research, 11242-11251.

Gurunada, J.P. (2020). The Google Classroom Mobile Application as a Learning Tool in English Language Teaching for Pre-Service Teachers. SLELTEC 2020 Proceeding, British Council and Ministry of Education.

Hayati, M. \& Fattahzadeh, A. (2006). The effect of monolingual and bilingual dictionaries on vocabulary recall and retention of EFL learners. An International Online Journal, 6 (2), 15-134. http://newtech.coe.uh.edu/toolname.cfm?toolid=160\& toolname=Schoolog y

Klimova, B \& Berger, A. (2018). Evaluation of the Use of Mobile Application in Learning English Vocabulary and Phrases - A Case Study. Springer. 3-11

Klimova, B. (2019). Mobile application as Appropriate Support for the Retention of New English Words and Phrases in English-Language Learning. Springer, 6.

Klimova, B. (2019). Mobile application as Appropriate Support for the Retention of New English Words and Phrases in English-Language Learning. Springer, 6.

Lacher, Lisa. (2018). Using discord to understand and moderate collaboration and teamwork. Proceedings of the $49^{\text {th }}$ ACM Technical Symposium on Computer Science Education, 1107-1107

Laufer, B. \& Levitzky-Aviad, T. (2006). Examining the effectiveness of bilingual dictionaries plus a dictionary for production in a foreign language. International of Lexicography, 190 (2), 135-155.

Marshall, C., \& Rossman, G. B. (2006). Designing Qualitative Research. London: Sage

Mehdipour, Y., \& Zerekahfi, H. (2013). Mobile Learning for Education: Benefit and Challanges. International Journal of Computational Engeenering Research, 93-101.

Muthia, A, et.al. (2018). Blended Learning Using Schoology as an Online Learning Platform. $2^{\text {nd }}$ English Language and Literature International Conference (ELLiC) Vol 2. 171-175

Nalliveettil, G. M \& Alenazi, T. H. K. (2016). The Impact of Mobile devices on English Language Learning: Perceptions of EFL Undergraduates. Journal of Language Teaching and Research Vol. 7 No. 2. 264-272.

Nation, I. S. P. (2013). Learning vocabulary in another language. Cambridge: Cambridge University Press.

Ninoriya, S., et.al. (2011). CMS, LMS and LCMS For eLearning. IJCSI International Journal of Computer Science Issues, Vol. 8, (2). 
Oz, H. (2013). Prospective English Teachers' Ownship and Usage of Mobile Device as M-Learning Tools. Proceedia-Sosial and Behavioral Sciences, 1031-1041.

Pardede, P. (2019) Integrated Skills Approach in EFL Classrooms: A Literature Review. In: PROCEEDING English Education Department Collegiate Forum (EED CF). UKI Press, Indonesia, Jakarta, pp. 147-159.

Pilar, R.-A., Jorge, A., \& Cristina, C. (2013). The use of Current Mobile Learning Application in EFL. Proceedia Social and Behavioral Science, 1190-1196.

Prashant, P.D. (2018). Importance of pronunciation in English language communication. Voice of Research.

Rahayu, I.S.D \& Purnawarman, P. (2018). The Use of Quizziz in Improving Students' Grammar Understanding through Self-Assessment. Advances in Social Science, Education and Humanities Research $11^{\text {th }}$ Conference on Applied Linguistics (CONAPLIN). -

Rezaei, M. \& Davoudi, M. (2016). The Influence of Electronic Dictionaries on Vocabulary Knowledge Extension. Journal of Education and Learning; Vol. 5, No. 3

Sana'ababneh. (2017). Using Mobile devices in Learning English: The Case of Jordan. Journal of Education and Human Development Vol 6, No. 4. 120128.

Steel, C.H. (2017). Enabling Effective Mobile Language Learning: Students' Perspectives, Wants and Needs. Spinger. 523-539

Sudarsana, K.I., et.al. (2019). The use of Google classroom in the learning process. IOP Conf. Series: Journal of Physics: Conf. Series 1175012165

Turnbull, D., et.al. (2019). Learning Management Systems: An Overview. A. Tatnall (ed.), Encyclopedia of Education and Information Technologies.

Wulanjani A.N. (2018). Discord Application Turning a Voice Chat Application for Gamers into a Virtual Listening Class. ELLiC Proceedings Vol. 2.

Yang, J. (2013). Mobile Assisted Language Learning: Review of the Recent Applications of Emerging Mobile Technology. English Language Teaching, 19-25.

Zou, B \& Li, J. (2015). Exploring Mobile Applications for English Language Teaching and Learning. In F Helm, Bradley, M. Guarda, \& S. Thouesny (Eds). Critical CALL - Proceedings of the 2015 EUROCALL Conference, Padova, Italy (pp. 564-568). Dublin: Research-publishing. net. http://dx.doi.org/10.14705/rpnet.2015.000394 